\title{
Editorial
}

\section{Diabetes, Diabetic Complications and Natural Products}

\author{
Yogesh A. Kulkarni* \\ SPP School of Pharmacy \& Technology Management, SVKM's NMIMS, Mumbai, Maharashtra, India
}

Diabetes mellitus (DM) includes a group of syndromes characterized by hyperglycemia; altered metabolism of lipids, carbohydrates, and proteins; and an increased risk of complications from vascular disease. Diabetes mellitus, a global public health problem, is now emerging as an epidemic world over. The prevalence of diabetes for all agegroups worldwide was estimated to be $2.8 \%$ in 2000 and $4.4 \%$ in 2030 . The total number of people with diabetes is projected to rise from 171 million in 2000 to 366 million in 2030 [1]. The global prevalence of diabetes is $8.3 \%$ and as per the estimation of 'International Diabetes Federation' in year 2013, 382 million people in the world are suffering from diabetes and another 316 million are at high risk of diabetes due to impaired glucose tolerance. The number is increasing and projected to reach 471 million by 2035 [2]. $\mathrm{DM}$ is a prime cause of excess cardiovascular morbidity and mortality. Other serious morbidities and mortalities are related to development of complications like nephropathy (kidney damage), neuropathy (nerve damage), and retinopathy (blindness) due to diabetes. Thus increasing prevalence of diabetes is responsible for a rise in the number of people suffering from diabetic complications. As a result, the share of diabetes in the death rate is also increasing worldwide. Thought there is heterogenicity in enormity and geographical distribution of prevalence, diabetes has become a major problem to be tackled by the healthcare systems globally. Despite tremendous advances in medicine during the past century, there is still no cure, which means that effective prevention and treatment are of paramount importance to prevent future increases in disease burden [3, 4].

There is an urge to find out an efficient and economic way to manage diabetes and its complications. The scientists are coming up with new synthetic molecules, but they are have a range of limitations including their side effects and the total treatment cost.

On this backdrop, the use of natural products is gaining popularity among the people. Plants have always been an exemplary source of drugs and many of the currently available drugs have been derived directly or indirectly from them. If we look into the history of the use of plants as

*Address correspondence to this author at the SPP School of Pharmacy \& Technology Management, SVKM's NMIMS, Mumbai, Maharashtra, India; Tel: 9122 42332000; Fax: 9122 26185422;

E-mail: yogeshkulkarni101@yahoo.com medicine, it can be traced back to the ancient days and they are as old as mankind itself. Natural product preparations have historically been the major source of pharmaceutical agents which also have an important role in the development of modern medicinal system. Metformin, the drug of choice for the treatment of diabetes is also linked with natural source. WHO is also promoting herbal medicines as a source of less expensive, comprehensive medical care especially in developing countries.

The literature quotes over 900 plants supposed to be useful in treatment traditionally [5] and some of them have also received scientific and medical evaluation to assess their efficacy.

Scientists are also working on natural products to explore their use in diabetes and its complications. Flavonoids and tannins are emerging classes of phytochemicals for their effects in diabetes. Many isolated constituents from natural sources have shown significant effects in diabetic complications. Research has proved the usefulness of natural products and supported the claims for their use.

The screening of these classes of compounds or isolated constituents has reached upto preclinical level, however, only few drugs have gone from plant to pharmacy.

So there is an unmet need for in depth research which will lead to discovery of some new drugs for the treatment or management of diabetes and its complication.

This special issue is devoted to natural products and their use in diabetes and its complications. It includes three research and three review articles focusing on the use of natural products for diabetes and its complications like retinopathy, cardiovascular myopathy, nephropathy. It also includes reviews focusing on therapeutic and mechanistic approach of use of these products. We look forward to provide the readers with the knowledge of the recent happenings in the field of diabetes and herbal medicines.

\section{CONFLICT OF INTEREST}

The authors confirm that this article content has no conflict of interest.

\section{ACKNOWLEDGEMENTS}

The Guest Editor of this Special Issue would like to thank all the reviewers who have spent their valuable time 
for providing comments to the authors. He would also like to thank all contributors for making this issue an important asset to the journal.

\section{PATIENT'S CONSENT}

Declared none.

\section{REFERENCES}

[1] Wild, S.; Roglic, G.; Green, A.; Sicree, R.; King, H. Global prevalence of diabetes: estimates for the year 2000 and projections for 2030. Diabet. Care, 2004, 27, 1047-1053.
[2] Hirst, M. International Diabetes Federation Atlas of Diabetes, $6^{\text {th }}$ ed., 2013, 07.

[3] Von, B. Type 1 diabetes: focus on prevention. Nat. Med., 2004, 10 783-784.

[4] Mayor, S. International Diabetes Federation consensus on prevention of type 2 diabetes. Int. J. Clin. Pract., 2007, 61, 1773-1775.

[5] Graham, J.; Farnsworth, N. The NaPRAlert database as an aid for discovery of novel bioactive compounds. In Comprehensive Natural Products 2: Chemistry and Biology. Development and Modification of Bioactivity; Elsevier; Amsterdam, Netherlands 2010, 3, pp. 81-93.

\section{(C) Yogesh A. Kulkarni; Licensee Bentham Open.}

This is an open access article licensed under the terms of the Creative Commons Attribution Non-Commercial License (http://creativecommons.org/licenses/by-nc/3.0/) which permits unrestricted, non-commercial use, distribution and reproduction in any medium, provided the work is properly cited. 